\title{
Exploring the views and experiences of HIV positive patients treated for cancer: a systematic review of the literature
}

HIV and Cancer Dual Diagnosis: the literature

Authors:

Emma G HAINSWORTH Department of Primary Care and Population Sciences, University College London, London, UK

Maryam SHAHMANESH Department of Infection and Population Health Mortimer, Institute of Global Health, University College London, London, UK

Fiona STEVENSON Department of Primary Care and Population Sciences, University College London, London, UK

\section{Corresponding Author:}

Emma Hainsworth. UCLH Cancer Clinical Trials Unit. $1^{\text {st }}$ Floor East, 250 Euston Road, London NW1 2PG. Email: emma.hainsworth@nhs.net 


\section{Exploring the views and experiences of HIV positive patients treated for cancer: a systematic review of the literature}

\section{Abstract. Structured Summary}

Objective: A systematic review of the literature was conducted to find out what is known about patients' experiences of a dual diagnosis of HIV and cancer

Design: A systematic review

Methods: We systematically searched the following databases; MEDLINE (Ovid Version); CINAHL Plus; PsycINFO and EMBASE from inception to June 2016 for studies that included patients with a dual diagnosis of cancer and HIV and focused on patient experiences. Studies with a focus on one illness rather than a dual diagnosis, those that focused on treatment strategies and medical management, epidemiology and pathology studies and comparison studies were all excluded. The full text of the included studies was reviewed. Information on location, sample size, study design and a narrative summary of findings were extracted using a standardised format. Studies were combined thematically.

Results: 1777 records were screened by title and abstract using the selection criteria described in the methods. Eight records were reviewed in depth in full text and seven selected as eligible. The selected studies suggest that a dual diagnosis of HIV and cancer has a powerful impact on individuals' behaviour. The experience of stigma was a consistent factor in all patient accounts.

Conclusions: This is an area largely unexplored in the published literature; further research into patients' experiences of a dual diagnosis or HIV and cancer will provide relevant knowledge in order to tailor and improve services. (228 words) 
Keywords: HIV/AIDS, Cancer, dual diagnosis, patient experience 


\section{Introduction}

Effective HIV treatment and continued HIV incidence means the number of people living with HIV/AIDS (PLHIV) has been increasing. Worldwide it reached 38.8 million in 2015. Wang et al. (2015). In the UK there were an estimated 107,800 PLHIV in 2013. Yin et al. (2014). One in four of PLHIV are now aged 50 years and over and consequently we are seeing more non AIDS-related malignancies in this ageing population and an associated increase in numbers of people with a dual diagnosis of HIV and Cancer needing to navigate two systems of specialised services. Those people with HIV who are more likely to develop malignancies; namely those who are diagnosed late with HIV or who are poorly engaged or disengaged with treatment, are a particularly vulnerable group. The START trial indicated that viral driven cancers such as Kaposi's sarcoma and lymphoma occurred more often in those people who started HAART (Highly Active Antiretroviral Therapy) later (later in this case being a CD4 count less than 500 cells $/ \mathrm{mm}^{3}$ ). INSIGHT START Study Group (2015). This group may pose a particular challenge to the provision of dual care in two conditions which are both serious and in which diagnosis can be distressing and frightening.

As PLHIV increasingly engage with cancer services their experiences are important to inform healthcare provision. Outcomes for both conditions rely on engagement and trust in the health system and this will be influenced by their experiences. The National Cancer Patient Experience Survey of 2014 showed that patient groups with an existing chronic condition, or from an ethnic or sexual minority, were less likely to be positive about their experiences of cancer care and treatment. Quality Health (2014), Pinder, Ferguson and Moller (2016). Investigation into the views, attitudes and experiences of PLHIV who are often from marginalised communities will provide insights which will allow care to be better tailored with the aim of improving outcomes. 
Literature which looks specifically at patients' experiences is an important addition to the body of knowledge which has been used as a means to improve care in other disease areas such as diabetes self-management and adherence to breast cancer treatment. Heisler, Bouknight, Hayward, Smith \& Kerr (2002); Kahn, Schneider, Malin \& Epstein (2007). An understanding of patients' experiences can help to provide a context and explanation for issues such as late presentation with symptoms of HIV or cancer, information requirements around diagnosis and treatment and adherence to treatment for both conditions. There are strong links between being involved in decision-making and feeling information is communicated effectively and improved safety and better clinical outcomes. Doyle, Lennox \& Bell (2013). For this particular group of patients it is important to identify the common drivers of good experience in order to inform improvement in services offered. Ziebland and colleagues (2013) present patient experience as a key component of healthcare quality and this is reinforced by NHS policy drivers such as the NHS Constitution of 2015 and the responses to the Francis Report of the Mid-Staffordshire NHS Foundation Trust Public enquiry. Department of Health (2015), Mid Staffordshire NHS Foundation Trust (2013). For HIV services, data on patient experiences are vital for raising awareness around the experience of cancer and collaborative working with cancer services; from the cancer services perspective it is important to understand implications for the management of complex patients presenting with pre-existing conditions.

Given the growing number of people who will be affected by a dual diagnosis of HIV and Cancer, many of whom will be from marginalised communities, the importance of understanding patients' experiences in order to improve outcomes is an important area of enquiry. 


\section{Methods}

A review of the literature relating to the experiences of HIV positive patients with a dual diagnosis of cancer was conducted. The review deliberately employed broad inclusion criteria and was constructed to include all study designs. Studies with a purely medical focus such as antiretroviral/chemotherapy management, epidemiology studies or those with a biology or pathology focus were excluded if they did not provide any perspective on patients' experiences of care.

\section{Search strategy and selection criteria}

The following databases were searched from their inception to June 2016 : MEDLINE (Ovid Version); CINAHL Plus; PsycINFO; and EMBASE. These databases were selected to provide an extensive coverage of the biomedical literature as well as including literature from psychology, nursing and allied health fields where one might expect information on patients' experiences to be found. Reference lists of included papers were reviewed and contact was made with authors. A university librarian provided expert guidance on the appropriate use of keyword and thesaurus terms within a comprehensive search strategy. The literature search used the following terms (with synonyms and closely related words): 'cancer' and 'HIV' or 'AIDS' combined with ['interviews as topic' or 'qualitative research' or 'experience' or 'patient satisfaction']

The search was tailored to find research most likely to yield useful information on patient experience (defined by The Beryl Institute as 'the sum of all interactions, shaped by an organisation's culture, that influence patient perceptions across the continuum of care'). The Beryl Institute Website (Accessed February 2017). Qualitative research was used as one of a number of terms to capture literature on experience but the overall search was not limited by 
research method, study design, country of origin or language of publication. An example of the full strategy and terms is provided in Table 1.

\begin{tabular}{|l|l|l|}
\hline & Ovid Medline Search 2nd August 2016 & \\
\hline & Search terms & Results \\
\hline 1 & $\begin{array}{l}((\text { cancer* or neoplasm* or tumo?r* or carcinoma*) adj3 (diagnos* or } \\
\text { treat* or therap*).mp. }\end{array}$ & 429125 \\
\hline 2 & exp Neoplasms/di, dt, pc, th & 1092739 \\
\hline 3 & 1 or 2 & 1312382 \\
\hline 4 & exp HIV/ & 88751 \\
\hline 5 & exp HIV Infections/ & 249810 \\
\hline 6 & $\begin{array}{l}\text { (HIV or human immunodeficiency virus or acquired immunodeficiency } \\
\text { syndrome).mp. }\end{array}$ & 353937 \\
\hline 7 & AIDS-Related Opportunistic Infections/ & 20260 \\
\hline 8 & 4 or 5 or 6 or 7 & 358830 \\
\hline 9 & Interviews as Topic/ & 48322 \\
\hline 10 & Interview*.mp. & 301485 \\
\hline 11 & qualitative research/ & 28387 \\
\hline 12 & qualitative.mp. & 168648 \\
\hline 13 & experience*.mp. & 832382 \\
\hline 14 & px.fs. & 852048 \\
\hline 15 & exp Patient Satisfaction/ & 70859 \\
\hline 16 & Dual diagnosis/ & 3240 \\
\hline 17 & 9 or 10 or 11 or 12 or 13 or 14 or 15 or 16 & 1872211 \\
\hline 18 & 3 and 8 and 17 & $\mathbf{7 6 1}$ \\
\hline
\end{tabular}

Records were screened by title and abstract to include all studies featuring a dual diagnosis of HIV and Cancer with a focus on patient experience, including the perspectives of both patients and service providers. Studies with a focus on just cancer or HIV rather than a dual diagnosis were screened out. Of the remaining studies those which focused exclusively on treatment strategies and medical management, epidemiology and pathology studies and comparison studies were all excluded. A sample of $10 \%$ of the dual diagnosis results was independently screened and checked using the exclusion criteria above. Figure 1 features a flow chart to summarise the process. The full text of the remaining studies was reviewed and information on location, sample size, study design, and narrative summaries of findings were recorded using a data extraction form. 
Figure 1 Search Strategy

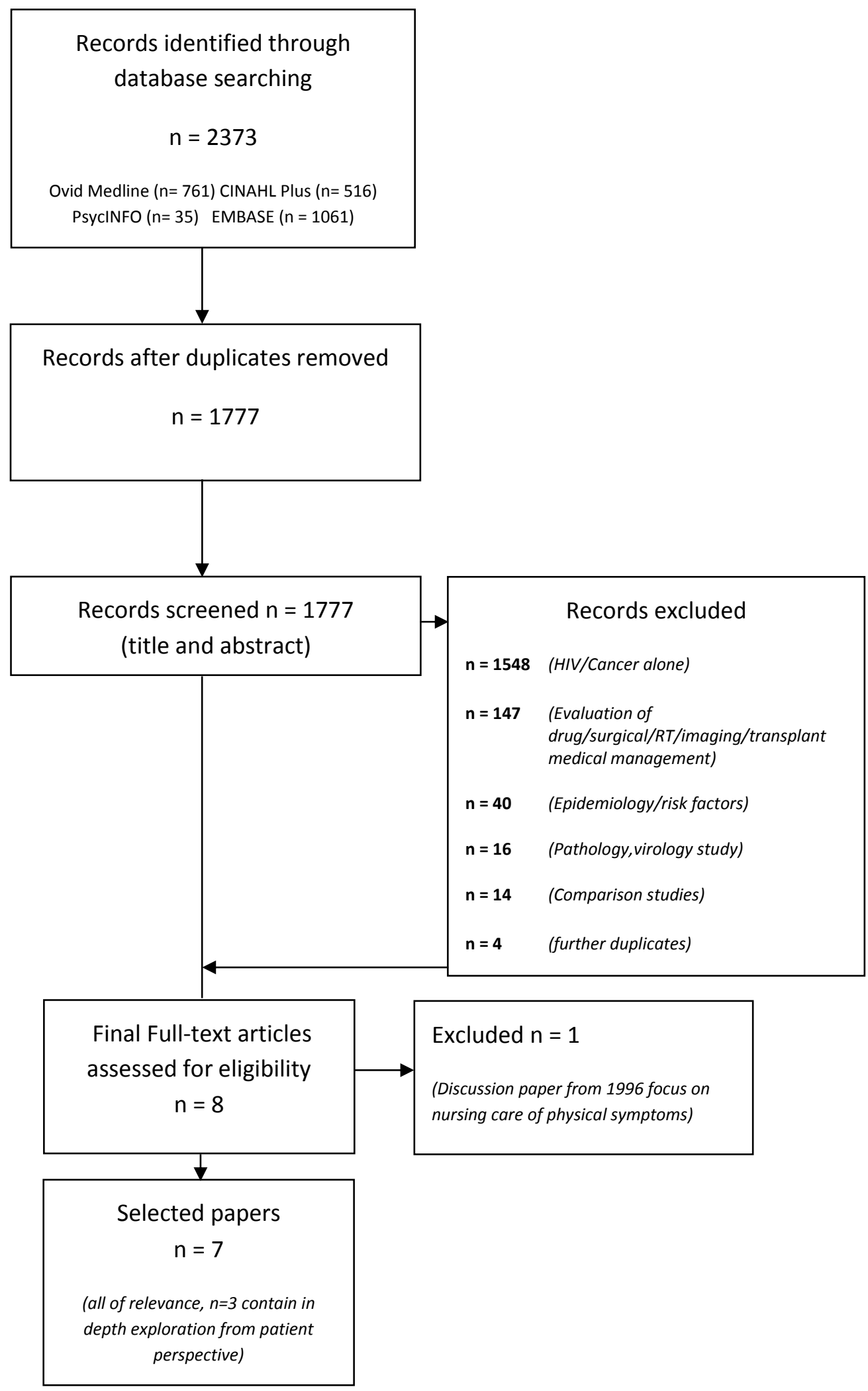




\section{Data Synthesis}

For each eligible study information about the sample such as the country it was drawn from and the gender and number of participants, along with a description of the research methods were noted. Studies were classified according to whether the aim was to represent service providers or the perspective of patients themselves. This process and the eligible studies are summarised in an evidence table, see Table 2. 
Table 2

\begin{tabular}{|c|c|c|c|c|c|c|c|c|}
\hline ference & Sample no & Sample characteristics & Location & Date & Question & Design/Methods & Results & Comments \\
\hline $\begin{array}{l}\text { Two for the price of one: life with a dual } \\
\text { diagnosis of HIV and Cancer Dodds N, HIV } \\
\text { Nursing. 8(1): 5-5. 2008 }\end{array}$ & $n=10$ & \begin{tabular}{|l|}
$\begin{array}{l}\text { Small cohort of gay men } \\
\text { with dual diagnosis of HIV } \\
\text { and Cancer }\end{array}$ \\
\end{tabular} & \begin{tabular}{|l|} 
London HIV \\
Oncology clinic
\end{tabular} & & $\begin{array}{l}\text { To understand the meanings \& language } \\
\text { that this group of patients ascribe to their } \\
8 \text { illiness }\end{array}$ & $\begin{array}{l}\text { Qual methods. 'Exploratory } \\
\text { ethnographic study using } \\
\text { observation and in depth } \\
\text { interviews' }\end{array}$ & \begin{tabular}{|l|} 
Findings include uncertain lead up \\
to diagnosis,selective disclosure of \\
illness, perception of \\
guilty/innocent illness, lack of \\
control with life-threatening nature \\
of cancer. Explaining cancer, link to \\
HIV, environment, stress
\end{tabular} & $\begin{array}{l}\text { Small, single site, looking at gay men only. } \\
\text { Very relevant in exploring patient } \\
\text { experience as described by patients } \\
\text { themselves. }\end{array}$ \\
\hline \begin{tabular}{|l|} 
The experience of African women \\
diagnosed with both HIV/AIDS and \\
cervical cancer. Maboko, E. Mavundla T.R. \\
Africa Journal of Nursing and Midwifery \\
8(1): 15-30. 2006 (MA in Public Health) \\
\end{tabular} & $n=8$ & \begin{tabular}{|l|} 
Purposive sample of \\
African women aged 31-42 \\
years diagnosed with HIV \\
and cervical cancer
\end{tabular} & \begin{tabular}{|l|} 
Radiotherapy \\
department \\
Johannesburg \\
hospital, South \\
Africa \\
\end{tabular} & & $\begin{array}{l}\text { How did the sample experience being } \\
\text { diagnosed with both HIV/AIDS and } \\
6 \text { cervical cancer? }\end{array}$ & $\begin{array}{l}\begin{array}{l}\text { Qual methods. In-depth } \\
\text { phenomenological } \\
\text { individual interviews and } \\
\text { field notes }\end{array} \\
\end{array}$ & $\begin{array}{l}\text { Themes emerge as importance of } \\
\text { communication; experience of } \\
\text { physical symptoms and emotional } \\
\text { experience }\end{array}$ & $\begin{array}{l}\text { A qualitative study looking at dual diagnosis } \\
\text { with HIV and cervical cancer. Findings } \\
\text { around selective disclosure, useful. Physical } \\
\text { symptoms less transferrable. Small sample, } \\
8 \text { participants, one type of cancer. African } \\
\text { setting. }\end{array}$ \\
\hline $\begin{array}{l}\text { Experiences of Batswana women } \\
\text { diagnosed with both HIV/AIDS and } \\
\text { cervical cancer. Molefe T; Duma SE. } \\
\text { Curationis. 32(4): 29-39. 2009 }\end{array}$ & $n=6$ & $\begin{array}{l}\text { Women diagnosed with } \\
\text { HIV and cervical cancer }\end{array}$ & \begin{tabular}{|l|} 
Oncology \& \\
gynaecology \\
department \\
tertiary hospital, \\
Botswana
\end{tabular} & 2007 & $\begin{array}{l}\text { What are the experiences of Batswana } \\
\text { women diagnosed with both HIV/AIDS } \\
7 \text { and cervical cancer? }\end{array}$ & $\begin{array}{l}\text { Qualitative methods. Semi- } \\
\text { structured interviews and } \\
\text { field notes, } \\
\text { phenomenological } \\
\text { approach }\end{array}$ & $\begin{array}{l}\text { Emergent themes, deep pain, fear } \\
\text { of the future/dying, intimate } \\
\text { loneliness, blaming others and } \\
\text { themselves, hope and spiritual } \\
\text { support, }\end{array}$ & $\begin{array}{l}\text { A qualitative study looking at dual diagnosis } \\
\text { with HIV and cervical cancer. Does not } \\
\text { explore how the 2illnesses interplay, how } \\
\text { they might differ from each other, rather the } \\
\text { themes arise from one entity the dual } \\
\text { diagnosis. Small sample, African setting, } \\
\text { using convenience sample }\end{array}$ \\
\hline $\begin{array}{l}\text { Predictors of timely access of oncology } \\
\text { services and advanced stage cancer in an } \\
\text { HIV-endemic setting. Brown, C. A., et al. } \\
\text { Oncologist 21(6): 731-738. 2016 }\end{array}$ & $n=1,146$ & Oncology patients & $\begin{array}{l}\text { Oncology } \\
\text { services in } 2 \\
\text { hospitals in } \\
\text { Southern } \\
\text { Botswana }\end{array}$ & 2014 & $\begin{array}{l}\text { Does engagement in longitudinal HIV care } \\
4 \text { improve access to timely oncology care? }\end{array}$ & \begin{tabular}{|l|} 
Baseline survey, and \\
review of records for \\
information on \\
symptom/rreatment \\
history, HIV testing for \\
those without a test in \\
previous 6 months. \\
Covariate descriptions and \\
measurement of time to \\
enrollment in oncology \\
care
\end{tabular} & \begin{tabular}{|l|} 
Longitudinal HIV care did not reduce \\
the substantial delay to cancer \\
treatment
\end{tabular} & $\begin{array}{l}\text { Survey collecting demographic information. } \\
\text { Interesting suggestion that receiving HIV } \\
\text { care does not raise awareness of cancer } \\
\text { symptoms and lead to earlier presentation }\end{array}$ \\
\hline \begin{tabular}{|l|} 
An innovative joint approach to HIV and \\
lymphoma care. Dhairyawan, R., S. \\
Longwill, et al. Sexually Transmitted \\
Infections 88(1):71.2012. (Letter)
\end{tabular} & $n=73$ & \begin{tabular}{|l|} 
Patients at novel specialist \\
HIV-haemato-oncology \\
clinic at London hospital
\end{tabular} & \begin{tabular}{|l} 
London NHS \\
Trust
\end{tabular} & $\begin{array}{l}\text { Nov } 2009 \text { - } \\
\text { April } 2010\end{array}$ & $\begin{array}{l}\text { Were patients satisifed with experience } \\
\text { of specialist clinic? }\end{array}$ & \begin{tabular}{|l|}
$\begin{array}{l}\text { Patient satisfaction } \\
\text { survey.Questions about } \\
\text { satitfaction with joint } \\
\text { clinic, ability to discuss } \\
\text { sensitive topics with } \\
\text { sufficient time. Response } \\
\text { rate 66\% }\end{array}$ \\
\end{tabular} & $\begin{array}{l}\text { High level of satisfaction, some } \\
\text { patients expressed desire for a } \\
\text { support group }\end{array}$ & $\begin{array}{l}\text { Service evaluation, not peer reviewed, one } \\
\text { clinic, letter,limited remit, survey rather } \\
\text { than qualitative enquiry into experience }\end{array}$ \\
\hline $\begin{array}{l}\text { Quality of life, characteristics and survival } \\
\text { of patients with HIV and Lymphoma. } \\
\text { Diamond C et al. Quality of Life Research. } \\
\text { 19(2): } 149-55,2010\end{array}$ & $n=100$ & \begin{tabular}{|l|}
50 patients with HIV \\
\&NHL, 50 patients with \\
NHL and no HIV using \\
population-based cancer \\
registry for Orange \& San \\
Diego Counties
\end{tabular} & $\begin{array}{l}\text { Cancer registry } \\
\text { for Orange \& San } \\
\text { Diego Counties, } \\
\text { California, Us }\end{array}$ & \begin{tabular}{|l|} 
Patients \\
diagnosed \\
$2002-2006$
\end{tabular} & $\begin{array}{l}\text { How do quality of life, characteristics and } \\
\text { survival compare between patients with } \\
\text { non Hodgkins lymphoma with and } \\
\text { without HIV? }\end{array}$ & $\begin{array}{l}\text { Patients completed } \\
\text { surveys: medical history, } \\
\text { QOL, FAHI and FACT G }\end{array}$ & $\begin{array}{l}\text { HIV infected NHL patients had } \\
\text { worse QOL \& survival than } \\
\text { uninfected patients due to } \\
\text { combination of co-morbidity, } \\
\text { aggressive histology and lack of } \\
\text { social support }\end{array}$ & $\begin{array}{l}\text { Quantitative methods, focus just on HIV \& } \\
\text { lymphoma but is relevant for dual diagnosis, } \\
\text { suggesting it may be more challenging for } \\
\text { both medical \& social reasons. Low social } \\
\text { well-being scores in dual diagnosis }\end{array}$ \\
\hline \begin{tabular}{|l|} 
At the intersection of HIV/AIDS and \\
cancer: a qualitative needs assessment of \\
community-based HIV/AIDS service \\
organizations. Burkhalter JE Et al Health \\
Education \& Behavior. 40(4): $493-503,2013$
\end{tabular} & $n=10$ & $\begin{array}{l}3 \times 7 \text { representatives from } \\
\text { community-based } \\
\text { organisations serving } \\
\text { people with HIV. }\end{array}$ & New York, us & \begin{tabular}{|l|}
4 month \\
period 2009 \\
2010
\end{tabular} & $\begin{array}{l}\text { To identify capacities, facilitators and } \\
\text { barriers to the uptake of cancer-focused } \\
\text { programmes by community organizations. }\end{array}$ & $\begin{array}{l}\text { Focus groups made up of } \\
\text { reps from community- } \\
\text { based organisations, } \\
\text { analysis of themes from } \\
\text { transcripts }\end{array}$ & \begin{tabular}{|l|} 
Agencies have limited experience, \\
need resources \& collaborative \\
partnerships to effectively \\
incorporate cancer services, staff \& \\
clients need education, cancer care \\
providers should be culturally \\
competent
\end{tabular} & $\begin{array}{l}\text { A qualitative study dealing with dual } \\
\text { diagnosis but looking from the perspective } \\
\text { of community based service providers not } \\
\text { from the perspective of the patients } \\
\text { themselves. Useful external light shed on } \\
\text { perceptions of cancer care providers not } \\
\text { being culturally competent }\end{array}$ \\
\hline
\end{tabular}




\section{Results}

\section{Study selection and characteristics}

The initial search strategy resulted in 1777 records which were screened by title and abstract using the selection criteria described in the methods. 1548 records were excluded as they dealt with HIV alone or Cancer alone. The remaining 229 records were screened and a $10 \%$ sample independently checked. The most frequent reason for exclusion was the study having a purely medical management focus; 147 records were excluded as they featured the evaluation of treatment strategies and clinical outcomes in the context of a dual diagnosis. 40 studies reporting epidemiological data on the prevalence and incidence of malignancy amongst the HIV population were also excluded along with 16 that had a biological, pathology focus. 14 studies that included a comparison between the experience of cancer patients and that of HIV patients were omitted as we were interested in exploration of dual diagnosis. Four papers were found to be further duplicates.

Eight full text records were reviewed in depth. One of these was excluded as a discussion paper; the remaining seven records all featured an aspect of the patient perspective and experience of a dual diagnosis of HIV and Cancer (see Table 2). Due to the small number of results and their disparate nature, the findings were combined thematically and summarised narratively.

\section{Patient perspective in studies employing a survey method}

Three studies represented patient experiences using cross-sectional surveys of patients with a dual diagnosis. Brown et al. (2016) conducted a survey in Botswana of 1,146 oncology patients collecting information on symptom and treatment history and offering HIV testing to those who had not had a test in the previous six months. They compiled covariate 
descriptions and measured time to enrolment in oncology care. They found that having been engaged in HIV care did not raise awareness of cancer symptoms and was not associated with an earlier presentation with them. Although this finding has interesting implications for HIV patients' experience of their cancer diagnosis, suggesting as it does that continued follow up in HIV services does not provide the opportunities to diagnose cancer earlier, there are problems with generalising the findings from two Botswanan hospitals beyond this setting and in particular to services in the UK.

In a US study Diamond, Taylor and Anton-Culver (2010) administered validated Quality of Life instruments; the Functional Assessment of Human Immunodeficiency Virus Infection (FAHI) in 50 patients with both HIV and Non Hodgkins Lymphoma (NHL), and the Functional Assessment of Cancer Therapy - General (FACT G) in 50 patients with NHL alone. The patients with a dual diagnosis had worse quality of life and survival than uninfected patients due to a combination of co-morbidity, aggressive histology and lack of social support. The finding of lower social well-being scores in the dual diagnosis group is relevant to an exploration of the patient experience in this group, although the study does not explore this in any depth and is limited to one particular malignancy.

The final survey was featured in a letter describing a service evaluation of a specialist HIV haemato-oncology clinic at a single London site; descriptive in nature and brief it represented patient experience by reporting 73 patients' feedback on their satisfaction with the joint service in terms of it providing the ability to discuss sensitive topics and sufficient time to do so. There was an expressed desire among patients for a support group and specific information sheets but the findings reported lacked detail and depth. Dhairyawan, Longwill, Orkin \& Montoto, (2012). 


\section{Service provider perspective}

One of the selected papers looked at dual diagnosis from the perspective of the service provider rather than the patient. A US study conducted three focus groups over a four month period in New York City. The groups were each made up of seven representatives from community based organisations who were selected because of the diversity of the populations they served and their extensive knowledge of the services and structure of their agencies. The focus groups explored the views of community based HIV service providers on what facilitators and barriers existed for them in offering support and information about cancer. Burkhalter et al., 2013. This provided an interesting perception on relevant issues, for example, some providers' perceptions of cancer services not being culturally competent, although it did not provide any direct information on patients' views and experiences.

\section{Patient perspective in studies using qualitative methods}

Three papers featured patients' perspectives of a dual diagnosis of HIV and Cancer using rich data which featured patients' perceptions and understandings and represented experiences with a depth of insight. Maboko and Mavundla (2006) and Molefe and Duma (2009) described two Southern African studies using in depth interviews and a phenomenological approach to explore the experience of women diagnosed with HIV and cervical cancer. Maboko (2006) performed in depth interviews with eight women with this dual diagnosis, aged between 31 and 42 years who attended the radiotherapy department in a Johannesburg hospital. The findings revealed that some patients chose to selectively disclose their cancer diagnosis and not their HIV diagnosis as a strategy to access social support. This feature of dual diagnosis is potentially of wider relevance, despite the study being focussed on one particular cancer in a South African setting. Molefe (2009) conducted semi-structured interviews with six women with both HIV and cervical cancer who were recruited from the 
oncology and gynaecology department in a tertiary hospital in Botswana. This study described isolation amongst the women, some of whom found it hard to maintain intimate relationships following their diagnosis and experienced feelings of guilt around their situation.

Dodds (2008) conducted an ethnographic study looking at a single UK site with a small cohort of ten gay men with a dual diagnosis of HIV and cancer. This study used observation and in-depth interviews to consider the meanings and language that patients ascribed to their illness. He found that different meanings and explanations were assigned to each condition and that having both diseases presented particular challenges including reinforcing experiences of stigma. Themes that emerged included a prolonged and difficult lead up to their cancer diagnosis and selective disclosure, with participants telling work colleagues, family and friends about their cancer diagnosis to elicit support whilst not disclosing their HIV status which they believed would carry the imputation of blame. These findings around selective disclosure support those of Maboko (2006). Perceptions of 'guilt' and 'innocence' in relation to illness were evident alongside patients' personal explanations and beliefs about what had caused their cancer. This study provided a highly relevant insight into patients' experiences of a dual diagnosis; it was, however, limited to a single site and a single cohort of gay men.

\section{Discussion}

This review found the experience of people living with a dual diagnosis of HIV and Cancer to be largely unexplored in the published literature. Patients experience the two diagnoses in different ways, coloured by the powerful cultural meanings and health beliefs that both conditions arouse. This impacts on the way in which they navigate social and healthcare; 
potentially impacting on health and quality of life outcomes. Given the increased number of people internationally who will be living with dual diagnosis this suggests a need to explore this under researched area.

The findings of the seven studies identified demonstrated that both HIV and cancer are illnesses linked to powerful beliefs and given cultural meaning in a way which impacts on an individual's sense of self, the way they behave and the social responses of others. Molefe (2009) described the increasing social isolation of women as a result of their dual diagnosis . A key theme emerging from both Maboko (2006) and Dodds (2008) was that of patients adopting a system of selective disclosure and talking primarily about their cancer diagnosis as a way of accessing social support. This differential disclosure in favour of their cancer diagnosis seemed to be a way of navigating stigma and negotiating complex social and health pathways. Other studies have identified this phenomenon in the dual diagnosis of HIV and other conditions. Accounts of patients with HIV and tuberculosis and HIV and Hepatitis C respectively, revealed how selective disclosure was adopted to manage stigma with both sets of participants sharing information about the illness that they felt to be less discrediting, with greater caution being applied to information about their HIV diagnosis. Daftary (2012); Lekas, Siegel, Leider (2011). Even though the samples were small and specific to very particular groups of patients the selected studies in this review all suggest that a dual diagnosis of HIV and cancer has a powerful impact on individuals behaviour and that stigma plays a key part.

The evidence suggests that patients diagnosed late with HIV, those who have disengaged with treatment, and vertically infected people, are at particularly risk of developing the virally driven cancers (e.g. lymphoma, cervical cancer and Kaposi sarcoma). INSIGHT START Study Group (2015). These patients are likely to be a particularly vulnerable group, and possibly members of marginalised populations experiencing stigma from more than one 
social structural category for example being gay or a migrant. We know that experience of stigma and the fear of disclosure of HIV status can affect adherence to HIV medication. Ware, Wyatt \& Tugenberg (2006). What is not known is how this HIV related stigma interplays with a patient's presentation with symptoms of cancer and adherence to cancer treatments.

Recent policy and practice discourse has framed HIV as a chronic disease like any other managed by routine medical management. Flowers (2010). This normalisation narrative in HIV relies upon the success of treatment and a focus on positive and healthy living. Mazanderini and Paparini (2015) have shown that tensions, challenges and contradictions to this narrative appear when stigma continues to affect people's work opportunities, social support systems and family life. When people with HIV experience health problems that don't match the normalised depiction they experience further discrimination from community groups who had embraced this approach. It is important to explore in future research how much a cancer diagnosis acts as a challenge to this HIV normalisation narrative.

\section{Limitations}

Publication bias may be a limitation of this review with the published data featuring empirical studies relating to the medical management of dual diagnosis, while the patients' experiences may feature more in the grey literature. There were a limited number of studies which it was not possible to combine making it harder to produce generalisable findings with confidence. Patient experience as a term is not always a clearly and consistently defined concept and this makes it difficult use in a systematic search of databases. 


\section{Conclusions}

This literature review suggests that further exploration of patients' experiences in the field of HIV and cancer dual diagnosis will add new knowledge relevant for tailoring improved services. The emerging themes around stigma and its effect on patients' access to social support and engagement with services suggest that future research should adopt methods which explore this complexity, capture change over time and generate deeper understandings of patients' behaviour. Patient agency interplays with stigma as can be seen with the strategy of selective disclosure; gaining a better understanding of this would provide opportunities to intervene and support service users. Such research in the future will help to provide a greater understanding of a dual diagnosis of cancer and HIV and how this can be managed most effectively for all concerned.

\section{Acknowledgements:}

EGH contributed to the development of the systematic review; reviewed articles for inclusion; extracted data; appraised quality of articles; created figures/tables; analysed data; and wrote the manuscript

MS contributed to the development of the research question and the methods for the systematic review; appraised quality of articles; contributed to interpretation of the findings and commented on all versions of the manuscript

FS contributed to the development of the research question and the methods for the systematic review; appraised quality of articles; contributed to interpretation of the findings and commented on all versions of the manuscript 
The study is being undertaken as part of a $\mathrm{PhD}$ at University College London. It is not in receipt of any funding

Conflicts of interest: There are no conflicts of interest 


\section{References}

Brown, C., Suneja, G., Tapela, N., Mapes, A., Pusoentsi, M., Mmalane,, M.... DrydenPeterson, S. (2016) Predictors of timely access of oncology services and advanced stage cancer in an HIV-endemic setting. Oncologist 21(6):731-738

Burkhalter, J., Cahill, S., Shuk, E., Guidry, J., Corner, G., Berk, A .....Lubetkin, E. (2013). At the intersection of HIV/AIDS and cancer: a qualitative needs assessment of community-based HIV/AIDS service organizations. Health Educ Behav 40(4): 493-503

Daftary, A. (2012). HIV and tuberculosis: The construction and management of double stigma. Soc Sci Med. 74 1512-1519

Department of Health. NHS Constitution for England. (2015). Retrieved from: www.gov.uk/government/publications/the-nhs-constitution-for-england

Dhairyawan R, Longwill S, Orkin C, Montoto S.(2012). An innovative joint approach to HIV and lymphoma care. Sex Transm Infect 88(1):71

Diamond, C., Taylor, T., Anton-Culver, H. (2010). Quality of life, characteristics and survival of patients with HIV and lymphoma. Qual Life Res 19(2): 149-155

Dodds, N. (2008). Two for the price of one: life with a dual diagnosis of HIV and cancer. HIV Nursing. 8(1):5-5

Doyle C, Lennox L, Bell D. A systematic review of evidence on the links between patient experience and clinical safety and effectiveness. BMJ Open 2013. 3: e001570

Flowers P. (2010). HIV transitions: consequences for self in an era of medicalization. In Davis M, Squire, C. (eds). HIV Treatment and Prevention Technologies in International Perspective. Basingstoke. Palgrave Macmillan; 109-125

Heisler, M., Bouknight, R., Hayward, R., Smith, D., Kerr, E. (2002). The Relative Importance of Physician Communication, Participatory Decision Making, and Patient Understanding in Diabetes Self-management. J Gen Intern Med,17(4):243-25221

INSIGHT START Study Group. (2015). Initiation of Antiretroviral Therapy in Early Asymptomatic HIV Infection. New Engl J Med 373(9): 795-807.

Kahn, K., Schneider, E., Malin, J., Epstein, A. (2007) Patient centred experiences in breast cancer: predicting long-term adherence to tamoxifen use. Med Care 45 (5): 431-9

Lekas, H., Siegel, K., and Leider, J. (2011). Felt and enacted stigma among HIV/HCVcoinfected adults: the impact of stigma layering. Qual Health Res 21(9): 1205-19

Maboko, E. and Mavundla, T.(2006). The experience of African women diagnosed with both HIV/AIDS and cervical cancer. Africa Journal of Nursing and Midwifery 8(1): 15-30

Mazanderani, F, and Paparini, S. (2015). The stories we tell: Qualitative research interviews, talking technologies and the 'normalisation' of life with HIV. Soc Sci Med 131: 66-73 
Mid Staffordshire NHS Foundation Trust (2013). Report of the Mid Staffordshire NHS Foundation Trust Public Inquiry - Executive Summary London: Crown Copyright

Molefe, T., and Duma, S. (2009). Experiences of Batswana women diagnosed with both HIV/AIDS and cervical cancer. Curationis 32(4):29-39

Pinder, R., Ferguson, J., \& Moller, H. (2016). Minority ethnicity patient satisfaction and experience: results of the National Cancer Patient Experience Survey in England. BMJ Open, $6(6)$

Quality Health (2014).Cancer Patient Experience Survey. Version 1.0. Retrieved from https://www.quality-health.co.uk/resources/surveys/national-cancer-experience-survey/2014national-cancer-patient-experience-survey/2014-national-cancer-patient-experience-surveynational-reports/688-2013-national-cancer-patient-experience-survey-national-report-pdf/file

The Beryl Institute Website, Defining Patient Experience (Accessed $1^{\text {st }}$ February 2017) http://www.theberylinstitute.org/?page=DefiningPatientExp.

Wang, H. Wolcock, TM., Carter, A., Nguyen, G., Kyu, HH. Gakidou, E.....Murray, C. (2015). Estimates of global, regional, and national incidence, prevalence, and mortality of HIV, 1980-2015: the Global Burden of Disease Study Lancet HIV ;3 (8) : e361 - e387

Ware, N., Wyatt, M., and Tugenberg, T.(2006). Social relationships, stigma and adherence to antiretroviral therapy for HIV/AIDS. AIDS Care, 18 (8): 904-10

Yin, Z., Brown, A., Hughes, G., Nardone, A., Gill, O., Delpech, V. \& contributors.(2014). HIV in the United Kingdom 2014 Report: data to end 2013. Public Health England, London

Ziebland, S., Coulter, A., Calabrese, J., Locock, L. (Eds). (2013). Understanding and using health experiences : improving patient care . Oxford : Oxford University Press. 